LA-UR-96- 1538

CONF- $961001-1$

Los Alamos National Laboratory is operated by the University of California for the United States Department of Energy under contract W-7405-ENG-36

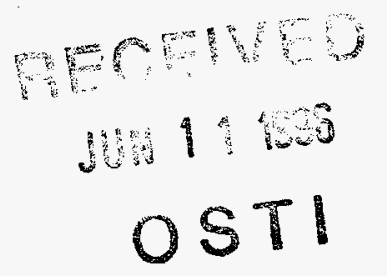

TTLE: A PARTICLE NUMERICAL MODEL FOR WALL FILM DYNAMICS IN PORT-INJECTED ENGINES

AUTHOR(S): $\quad$ P(eter) J. O'Rourke, T-3

A(nthony) A. Amsden, T-3

SUBmitTEd To: $\quad$ SAE Fuels and Lubricants Meeting, San Antonio, Texas, October 14-17, 1996

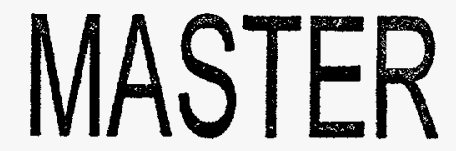

By acceptance of this article, the publisher recognizes that the U.S. Government retains a nonexclusive, royalty-free license to publish or reproduce the published form of this contribution, or to allow others to do so, for U.S. Government purposes.

The Los Alamos National Laboratory requests that the publisher identify this article as work performed under the auspices of the U.S. Department of Energy.
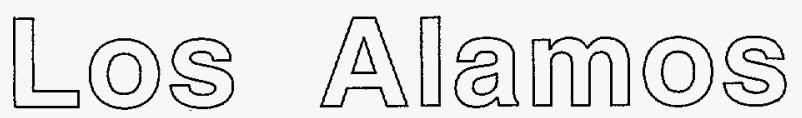

Los Alamos National Laboratory Los Alamos, New Mexico 87545 


\section{DISCLAIMER}

Portions of this document may be illegible in electronic image products. Images are produced from the best available original document. 


\title{
A PARTICLE NUMERICAL MODEL FOR WALL FILM DYNAMICS IN PORT-INJECTED ENGINES
}

\author{
P. J. O'Rourke and A. A. Amsden, Los Alamos National Laboratory
}

\section{ABSTRACT}

To help predict hydrocarbon emissions during cold-start conditions we are developing a numerical model for the dynamics and vaporization of the liquid wall films formed in port-injected spark-ignition engines and incorporating this model in the KIVA3 code for complex geometries. This paper summarizes the current status of our project and presents illustrative example calculations.

The dynamics of the wall film is influenced by interactions with the impinging spray, the wall, and the gas flow near the wall. The spray influences the film through mass, tangential momentum, and energy addition. The wall affects the film through the no-slip boundary condition and heat transfer. The gas alters film dynamics through tangential stresses and heat and mass transfer in the gas boundary layers above the films. New wall functions are given to predict transport in the boundary layers above the vaporizing films. It is assumed the films are sufficiently thin that film flow is laminar and that liquid inertial forces are negligible. Because liquid Prandtl numbers are typically about ten, unsteady heating of the film should be important and is accounted for by the model. The thin film approximation breaks down near sharp corners, where an inertial separation criterion is used. A limitation of the current model is its neglect of splashing caused by the impinging spray, and this will be removed in future work.

A particle numerical method is used for the wall film. This has the advantages of compatibility with the KIVA-3 spray model and of very accurate calculation of convective transport of the film. Its disadvantage is the need to track particles on curved surfaces, and we describe how this is accomplished.

We have incorporated the wall film model into KIVA-3, and the resulting combined model can be used to simulate the coupled port and cylinder flows in modern spark-ignition engines. We give examples by comparing computed fuel distributions with closed- and open-valve injection during the intake and compression strokes of a generic two-valve engine.

\section{INTRODUCTION}

Much research activity has been initiated by recent findings [1] that a large fraction of the hydrocarbon emissions of modern spark-ignition (SI) engines are generated in the first ten seconds after starting the cold engine. Solving this so-called cold-start problem would greatly help the automobile companies meet government-mandated hydrocarbon emission standards in the near future. The importance of the cold-start problem is indicated by the number of efforts to develop multidimensional numerical models that could give detailed information about how cold-start emissions originate and possible remedies for them [2-5]. The major new submodel needed before existing multidimensional models can predict cold-start emissions is that for the dynamics and vaporization of the wall films formed by port injection. This paper is a first reporting of a new multidimensional model being developed at Los Alamos for predicting film flows in port-injected SI engines. It differs from most other models principally in that the film is tracked by computational particles, leading to very accurate calculation of wall film transport. We also propose new wall functions for use with the $\mathrm{k} / \epsilon$ turbulence model to predict the transport of vapor mass, momentum, and energy in the turbulent boundary layers above the vaporizing wall films.

In some respects modeling the wall films formed in portinjected engines is easier than in direct-injected engines. Injection pressures of port injectors are typically much lower (less than $500 \mathrm{kPa}$ ) than cylinder injector pressures so that atomization is not so fine [6]. The resulting lower injection velocities give rise to less droplet splash and rebound from walls. Still, droplet splash is important and, although we have not yet included this effect in our model, it will be included in future work. A great simplification is that during cold start the temperatures on walls and the valve of the intake port are typically less than the boiling point temperatures of most components of gasoline. Thus we can assume that the liquid film is in direct contact with the wall and ignore other heat transfer regimes that occur when sprays impinge on hot cylinder walls, cylinder heads, and pistons [7].

Another great simplification that we and others make is the thin film approximation. This actually is comprised of a number of assumptions. First, it is assumed that film thicknesses are much smaller than radii of curvature of the walls and than characteristic distances along the wall surface over which mean properties vary. Second, we assume that the films are so thin that the liquid flow in them is laminar and the liquid velocities 
in the film are tangent to the wall (in the frame of reference of the wall) and vary linearly with height above the wall. Third, it is assumed that inertial and gravitational forces on the film are negligible. Fourth, we assume that the air flow velocities above the films are much larger than the film velocities and therefore that the air flow sees a "solid" surface in the computation of the air velocity relative to the film velocity. Order of magnitude arguments, some of which will be given in the equations section of this paper, show that most of these assumptions are valid as long as film thicknesses are less than approximately $100 \mu \mathrm{m}$.

Despite the many simplifications resulting from the thin film approximation, numerous challenges remain in modeling film dynamics and its coupling with the gas. One of these is the capability to predict flow separation of the film from the wall and subsequent re-entrainment of the liquid into the gas as droplets. One can show that separation can only occur at sharp corners, where the thin film approximation breaks down. Thus wall separation cannot be predicted by a thin film model, and a separate submodel must be formulated that predicts when such separation occurs and the properties (radii and velocities) of the liquid droplets that result. In this paper we propose a new inertial criterion for wall separation, and this will be described in the equations section. We do not account in our model for another possible re-entrainment mechanism -the stripping of droplets from the surface of the film due to unstable wave growth.

Another challenge is the prediction of heat, mass, and momentum transfer in the turbulent gas boundary layers above the films. For nonvaporizing circumstances, well-known $\mathrm{k} / \epsilon$ model wall functions have been formulated that in many situations predict turbulent wall drag and heat transfer reasonably well [8]. Because of the blowing velocities caused by vaporization, however, gas boundary layer structure above wall films will be altered, and the diffusive transport of momentum and energy in the boundary layers will be inhibited because of boundary layer thickening. In this work we propose new wall functions that reduce to a standard formulation for nonvaporizing circumstances and account for the inhibition of transport in the boundary layers above vaporizing surfaces. Experimental validation and refinement of these wall functions will be performed in future work.

A third challenge is a numerical one and concerns the accurate calculation of convective transport of the film. Surface tension keeps the edges of the films sharp, but many current numerical models, because they use continuous-fluid methods to solve the film equations [2,4,5], will diffuse the edges of the film over several surface computational cells. This surface grid is usually very coarse, and considerable numerical thinning of the film can result, leading to large errors because so much of the film dynamics and vaporization depend on film thickness. To overcome this problem we use a particle method to represent the wall film. Particle methods have long been successfully used to track interfaces in fluid dynamics calculations $[9,10]$. Another advantage of a particle method is its compatibility with the particle spray model that is used by the KIVA code [11]. A disadvantage of a particle model is the need to move wall particles and keep them on curved wall surfaces. Reference [3] describes a particle film model, but the film does not move along walls. Reference [12] presents a particle film model for diesel engines but ignores film vaporization and does not describe how the film particles are moved.
The remainder of this paper is organized as follows. In the next section we discuss the wall film equations that we are solving. Some of the assumptions of the thin film approximation will be justified at this time, and we present the new wall functions for boundary layers above vaporizing films. The particle numerical method will be described in the third section, where we tell how we move particles on the curved wall surfaces. The numerical method has been incorporated into the KIVA-3 code [13] for complex geometries, and the last section describes two calculations of closed- and open-valve injection in a generic two-valve SI engine.

\section{THE WALL FILM EQUATIONS}

In this section we give the equations for wall films and their coupling to the gas and the spray. The derivation of the equations is quite lengthy will not be given. We do give the physical assumptions made in deriving the equations, and in some cases we justify these with order of magnitude estimates. We first present the mass, momentum, and energy equations for wall films. Then the coupling of these equations to the gas equations will be given. Third, we present the new wall functions and give some of their properties. Finally, we tell of a new inertial separation criterion for the prediction of flow separation of wall films at sharp corners.

WALL FILM MASS EQUATION - The mass equation for wall films is not directly solved because the computational particle method we use automatically conserves wall film mass. Nevertheless, we give the mass equation here because it allows us to introduce some necessary notation:

$$
\frac{\partial \rho_{\ell} h}{\partial t}+\nabla_{s} \cdot\left[\rho_{\ell}\left(\overline{\mathbf{u}}_{\ell}-\mathbf{v}_{w}\right) h\right]=\dot{M} .
$$

In this equation

$$
\begin{aligned}
\rho_{\ell}= & \text { liquid density (assumed constant) } \\
h= & \text { film thickness, } \\
\frac{\partial}{\partial t}= & \text { time-rate-of-change in the frame of reference } \\
& \text { of the wall, } \\
\nabla_{s}= & \text { surface gradient operator, } \\
\overline{\mathbf{u}}_{\ell}= & \text { mean film velocity in the laboratory frame, and } \\
\mathbf{v}_{w}= & \text { wall velocity. }
\end{aligned}
$$

$\dot{M}$ is the mass source per unit wall area due to impingement, re-entrainment, or vaporization:

$$
\dot{M}=\dot{M}_{\text {imp }}+\dot{M}_{\text {rent }}+\dot{M}_{\text {vap }}
$$

The re-entrainment source will be specified later when the wall separation model is presented. The impingement source is

$$
\dot{M}_{\mathrm{imp}}=\iiint_{\mathbf{v} \cdot \mathbf{n}<0} \frac{4}{3} \pi r^{3} \rho_{\ell} \mathbf{v} \cdot \mathbf{n} f\left(\mathbf{x}_{s}, \mathbf{v}, r, T_{d}, t\right) d \mathbf{v} d v d T_{d},
$$

where $f$ is the spray droplet distribution function [11], $\mathbf{n}$ is the unit normal to the wall pointing into the gas, and $\mathbf{x}_{s}$ is a point on the wall surface. Thus, we are assuming that every droplet that hits the wall becomes part of the wall film. The vaporization 
source $\dot{M}_{\text {vap }}$ will be given later when the wall functions are described.

WALL FILM MOMENTUM EQUATION - To compute the film velocity $\overline{\mathbf{u}}_{\ell}$ we approximate the following film momentum equation:

$$
\begin{aligned}
0=\tau_{w} \mathbf{t} & -\mu_{\ell}\left(\bar{T}_{\ell}\right) \frac{\overline{\mathbf{u}}_{\ell}-\mathbf{v}_{w}}{h / 2}+\dot{\mathbf{P}}_{\mathrm{imp}}-\left(\dot{\mathbf{P}}_{\mathrm{imp}} \cdot \mathbf{n}\right) \mathbf{n} \\
& +\dot{M}_{\mathrm{imp}}\left[\left(\mathbf{v}_{w} \cdot \mathbf{n}\right) \mathbf{n}-\overline{\mathbf{u}}_{\ell}\right]
\end{aligned}
$$

where

$$
\begin{aligned}
\tau_{w} & =\text { shear stress on top (gas-side) of the film, } \\
\mathbf{t} & =\text { unit tangent to the surface in direction of } \overline{\mathbf{u}}_{\ell}-\mathbf{v}_{w}, \\
\mu_{\ell} & =\text { liquid viscosity (temperature-dependent), } \\
\bar{T}_{\ell} & =\text { mean film temperature, and } \\
\dot{\mathbf{P}}_{\text {imp }} & =-\iiint_{\mathbf{v} \cdot \mathbf{u}<0} \frac{4}{3} \pi r^{3} \rho_{\ell} \mathbf{v v} \cdot \mathbf{n} f\left(\mathbf{x}_{s}, v, r, T_{d}, t\right) d r d \mathbf{v} d T_{d} .
\end{aligned}
$$

Thus we are assuming that the velocity of the film is determined by a balance of the shear stress forces exerted on the top of the film by the gas boundary layer, viscous forces in the film arising from the difference between the mean film velocity and the wall velocity, and forces exerted by an impinging spray. We further assume that normal stresses in the film bring about instantaneous equilibration of the normal components of the film and wall velocities. Thus by dotting Eq. (3) with the wall normal $\mathbf{n}$ one obtains $\left(\mathbf{u}_{\ell}-\mathbf{v}_{w}\right) \cdot \mathbf{n}=0$. The expression we use for $\tau_{w}$ will be given later.

Equation (3) is derived by subtracting $\mathbf{u}_{\ell}$ times the film mass equation from the full film momentum equation and making the following assumptions:

1. wall film inertial terms are negligible,

2. pressure gradient terms are negligible,

3. gravitational forces are negligible,

4. changes in the film velocity due to vaporization are negligible, and

5. the velocity profile in the film varies linearly with distance from the wall.

All of these assumptions are justified if wall films are thin enough, and we only show here how thin the films must be in order that assumption 1 be valid. In regions where there is a balance between boundary layer shear stresses and viscous forces in the film

or

$$
\tau_{w} \approx \mu_{\ell} \frac{\mathbf{u}_{\ell}}{h / 2},
$$

$$
\mathbf{u}_{\ell} \approx \frac{\tau_{w} h}{2 \mu_{\ell}} .
$$

KIVA calculations of intake port flows give us characteristic values of the wall shear stress $\tau_{w}$ of 100 dynes $/ \mathrm{cm}^{2}$, and the viscosity of gasoline is approximately $5 \times 10^{-3} \mathrm{~g} /(\mathrm{cm} \mathrm{s})$. Thus by Eq. (4) liquid velocities in such regions are approximately $10^{4} h \mathrm{~cm} / \mathrm{s}$, where $h$ is measured in $\mathrm{cm}$. In magnitude, the inertial terms in the liquid film momentum equation are

$$
I \approx \rho_{\ell} \mathbf{u}_{\ell}^{2} \frac{h}{L},
$$

where $L$ is a characteristic distance along the surface over which the liquid velocity varies. Taking $L \approx 1 \mathrm{~cm}$ and using Eq. (4) gives $I \approx 10^{8} h^{3}$. Thus if $h<10^{-2} \mathrm{~cm}=100 \mu \mathrm{m}$ then $I$ will be less than $\tau_{w}$, and inertial terms can be neglected.

WALL FILM ENERGY EQUATION - In contrast to the momentum equation, we cannot ignore the unsteady or convective transport terms in the wall film energy equation. This is because liquid Prandtl numbers are typically about 10 , and therefore characteristic heat conduction times are an order of magnitude longer than viscous transport times. Likewise it cannot be assumed that the temperature profile in the film is linear. Accurate numerical calculation of the film temperature would require discretizing the liquid film in layers and formulating finite difference equations for the temperature in each layer. This alternative would be very costly computationally, and we instead solve for the mean film temperature $\bar{T}_{\ell}$ and approximate the temperature profile to be piecewise linear, varying from the wall temperature $T_{w}$ to $\bar{T}_{\ell}$ in the lower half of the film and from $\bar{T}_{\ell}$ to a gas surface temperature $T_{s}$ in the upper half of the film. The film energy equation is

$$
\begin{aligned}
\rho_{\ell} h C_{v_{\ell}} & \left\{\frac{\partial \bar{T}_{\ell}}{\partial t}+\left[\left(\overline{\mathbf{u}}_{\ell}-\mathbf{v}_{w}\right) \cdot \nabla_{s}\right] \bar{T}_{\ell}\right\} \\
& =\lambda_{\ell}\left(\bar{T}_{\ell}\right)\left[\frac{T_{s}-\bar{T}_{\ell}}{h / 2}-\frac{\bar{T}_{\ell}-T_{w}}{h / 2}\right] \\
& +\dot{Q}_{\mathrm{imp}}-I_{\ell}\left(\bar{T}_{\ell}\right) \dot{M}_{\mathrm{imp}}
\end{aligned}
$$

where

$$
\begin{aligned}
C_{v_{\ell}}= & \text { liquid specific heat (temperature-dependent), } \\
\lambda_{\ell}= & \text { liquid heat conductivity (temperature-dependent) } \\
I_{\ell}\left(\bar{T}_{\ell}\right)= & \text { liquid internal energy at temperature } \bar{T}_{\ell}, \\
T_{w}= & \text { wall temperature, and } \\
\dot{Q}_{\text {imp }}= & -\iiint_{\mathbf{v} \cdot \mathbf{n}<0} \frac{4}{3} \pi r^{3} \rho_{\ell} I_{\ell}\left(T_{d}\right) \mathbf{v} \cdot \mathbf{n} f \\
& \left(\mathbf{x}_{s}, \mathbf{v}, r, T_{d}, t\right) d \mathbf{v} d r d T_{d} .
\end{aligned}
$$

The term in braces in Eq. (5) is the time-rate-of-change of temperature following a liquid film element moving along the wall surface. In addition to this unsteady term and the heat conduction terms, the mean film temperature $\bar{T}_{\ell}$ can change due to spray wall impingement. Equation (5) ignores the small changes in mean film temperatures due to vaporization of fuel at the surface of the film that is at a temperature $T_{s}$, which is different from the mean film temperature, and the changes in film temperatures due to correlations of fluctuating temperature and velocity within the film.

In order to calculate the film surface temperature, we need the interface conservation condition relating the gas-side heat transport $\dot{Q}$ to the film, the energy used to vaporize fuel, and the liquid-side heat transport due to conduction:

$$
\dot{Q}=\dot{M}_{\mathrm{vap}} \mathcal{L}\left(T_{s}\right)+\lambda_{\ell}\left(\bar{T}_{\ell}\right) \frac{T_{s}-\bar{T}_{\ell}}{h / 2},
$$

where $\mathcal{L}$ is the latent heat of vaporization. The expression we use for $\dot{Q}$ will be given later in the subsection on wall functions.

COUPLING TO THE GAS EQUATIONS - The coupling to the gas equations is through wall source terms $S_{\rho}, \mathbf{S}_{u}$, and $S_{I}$ in 
the mass, momentum, and internal energy equations solved by KIVA:

$$
\begin{aligned}
S_{\rho} & =\dot{M}_{\text {vap }} \delta\left(y-y_{s}\right) \\
\mathbf{S}_{u} & =\left[\dot{M}_{\text {vap }}\left(2 \overline{\mathbf{u}}_{\ell}-\mathbf{v}_{\text {wall }}\right)-\tau_{w} \mathbf{t}\right] \delta\left(y-y_{s}\right) \\
\text { and } \quad S_{I} & =\left[\dot{M}_{\text {vap }} h_{v}\left(T_{s}\right)-\dot{Q}\right] \delta\left(y-y_{s}\right)
\end{aligned}
$$

where $y$ is the coordinate normal to the wall surface, $y_{s}$ is the value of $y$ on the surface, and $h_{v}\left(T_{s}\right)$ is the fuel vapor enthalpy evaluated at the surface temperature. The next section gives the film mass vaporization rate $\dot{M}_{\text {vap }}$, the shear stress $\tau_{w}$ on the gas surface of the film, and the heat flux $\dot{Q}$ from the gas to the film. The detailed mass, momentum, and internal energy equations solved by KIVA-3 can be found in the KIVA-II documentation [11].

WALL FUNCTIONS FOR VAPORIZING FILMS - Vaporization alters the structure of the turbulent boundary layers above the wall films because of the gas velocities normal to the wall induced by vaporization and consequent convective transport away from the film of mass, momentum, and energy. The exact nature of the alteration is unknown, although qualitatively it should give rise to an inhibition of mass, momentum, and energy transport in comparison to the nonvaporization situation. We have derived provisional wall functions that have this property of inhibiting transport and that reduce to standard wall functions above nonvaporizing walls. Two major assumptions are made in the derivation of the wall functions in the fully turbulent region of the boundary layer. First, it is assumed that total transport is independent of the normal coordinate to the wall and is the sum of transport due to turbulent diffusion and due to convection by the vaporization velocities. Second, we assume that as in nonvaporizing boundary layers there is a linear variation of the turbulent diffusivity with distance from the wall.

The mass vaporization rate $\dot{M}_{\text {vap }}$ is given by

$$
\dot{M}_{\mathrm{vap}}=H_{Y} \ln \left(\frac{1-Y_{v}}{1-Y_{v_{s}}}\right)
$$

where

$$
H_{Y}= \begin{cases}\frac{\rho c_{\mu}^{1 / 4} K^{1 / 2}}{y_{c}^{+} S c_{\ell}+\frac{S c_{T}}{\kappa} \ln \left(\frac{y^{+}}{y_{c}^{+}}\right)} & y^{+}>y_{c}^{+} \\ \frac{\rho c_{\mu}^{1 / 4} K^{1 / 2}}{y^{+} S c_{\ell}} & y^{+}<y_{c}^{+}\end{cases}
$$

$Y_{v}=$ fuel vapor mass fraction at $y^{+}$,

$Y_{v_{s}}=Y_{v_{\mathrm{eq}}}\left(T_{s}\right)=$ equilibrium vapor mass fraction at film surface temperature,

$S c_{\ell}, S c_{T}=$ laminar, turbulent Schmidt numbers, and

$$
\kappa=\text { Karmann's constant }=0.433[11] \text {. }
$$

The dimensionless normal coordinate $y^{+}$is given by

$$
y^{+}=\frac{y c_{\mu}^{1 / 4} K^{1 / 2}}{v_{\ell}}
$$

where $v_{\ell}$ is the laminar kinematic viscosity. It is assumed that the transition between the fully turbulent region and the laminar profile near the wall occurs at a value $y_{c}^{+}$of 11.05 , independent of the mass vaporization rate.

The boundary layer shear stress and heat flux are both given in terms of a dimensionless vaporization rate $M^{*}$ :

$$
M^{*}=\frac{\dot{M}_{\mathrm{vap}}}{\rho c_{\mu}^{1 / 4} K^{1 / 2}}
$$

The shear stress is given by

$$
\frac{\tau_{w}}{\rho\left|\mathbf{u}-\mathbf{v}_{w}\right| c_{\mu}^{1 / 4} K^{1 / 2}}= \begin{cases}\frac{M^{*}}{e^{B M^{*}}\left(y^{+}\right)^{M^{*} / \kappa}-1} & y^{+}>y_{c}^{+} \\ \frac{M^{*}}{e^{M^{*} y^{+}}-1} & y^{+}<y_{c}^{+},\end{cases}
$$

where $B=5.5$ [11]. Note that the value of $y_{c}^{+}$has been chosen to give a continuous transition between the turbulent and laminar regions in Eq. (11), since $1 / \kappa \ln \left(y_{c}^{+}\right)+B=y_{c}^{+}$. Also note the use of $\left|\mathbf{u}-\mathbf{v}_{w}\right|$, rather than $\left|\mathbf{u}-\overline{\mathbf{u}}_{\ell}\right|$, in this expression, where $\mathbf{u}$ is the gas velocity at $y^{+}$. This is where we invoke the assumption that $\left|\mathbf{u}-\mathbf{v}_{w}\right| \gg\left|\overline{\mathbf{u}}_{\ell}-\mathbf{v}_{w}\right|$.

The boundary layer heat flux is given by

$$
\begin{aligned}
& \frac{\dot{Q}}{\rho c_{p} c_{\mu}^{1 / 4} K^{1 / 2}\left(T-T_{s}\right)}= \\
& \begin{cases}\frac{M^{*}}{e^{y_{c}^{+} M^{*} P r_{\ell}}\left(\frac{y^{+}}{y_{c}^{+}}\right)^{\frac{M^{*} P_{r_{T}}}{\kappa}}-1} & y^{+}>y_{c}^{+} \\
\frac{M^{*}}{e^{y+M^{*} P r_{\ell-1}}} & y^{+}<y_{c}^{+},\end{cases}
\end{aligned}
$$

where $P r_{T}$ and $P r_{\ell}$ are the turbulent and laminar Prandtl numbers.

In the limit of small $M^{*}$ Eqs. (11) and (12) reduce to

$$
\frac{\tau_{w}}{\rho\left|\mathbf{u}-\mathbf{v}_{w}\right| c_{\mu}^{1 / 4} K^{1 / 2}}= \begin{cases}\frac{1}{1 / \kappa \ln y^{+}+B} & y^{+}>y_{c}^{+} \\ \frac{1}{y^{+}} & y^{+}<y_{c}^{+}\end{cases}
$$

and

$$
\frac{\dot{Q}}{\rho c_{p} c_{\mu}^{1 / 4} K^{1 / 2}\left(T-T_{s}\right)}= \begin{cases}\frac{1}{y_{c}^{+} P r_{\ell}+\frac{P r_{x}}{\kappa} \ln \left(\frac{y^{+}}{y_{c}^{+}}\right)} & y^{+}>y_{c}^{+} \\ \frac{1}{y^{+} P r_{\ell}} & y^{+}>y_{c}^{+},\end{cases}
$$

which are standard wall functions for the turbulent boundary layers above nonvaporizing surfaces [8]. It can be shown that for a given value of $y^{+}$the shear stress and heat flux of Eqs. (13) and (14) are reduced from their values in Eqs. (11) and (12) if $M^{*}>0.0$.

WALL SEPARATION CRITERION - The coupling of the film with the spray is already partially accounted for above by the impingement functions $\dot{M}_{\mathrm{imp}}, \dot{\mathbf{P}}_{\mathrm{imp}}$, and $\dot{Q}_{\mathrm{imp}}$. These are used to calculate the response of the wall film when spray droplets become part of the film. In this section we give one way in which the spray responds when fuel in the film is converted into droplets. This can occur when the film flows over a sharp corner of the wall, such as the rim of the intake valve or an edge of the valve seat.

The wall geometry near the sharp edge is depicted in Fig. 1. The plane of Fig. 1 is the plane of the two normals $\mathbf{n}_{\mathbf{1}}$ and $\mathbf{n}_{2}$ to the surfaces on either side of the edge. The movement of the film is from surface 1 to surface 2 , but the film velocity relative to 

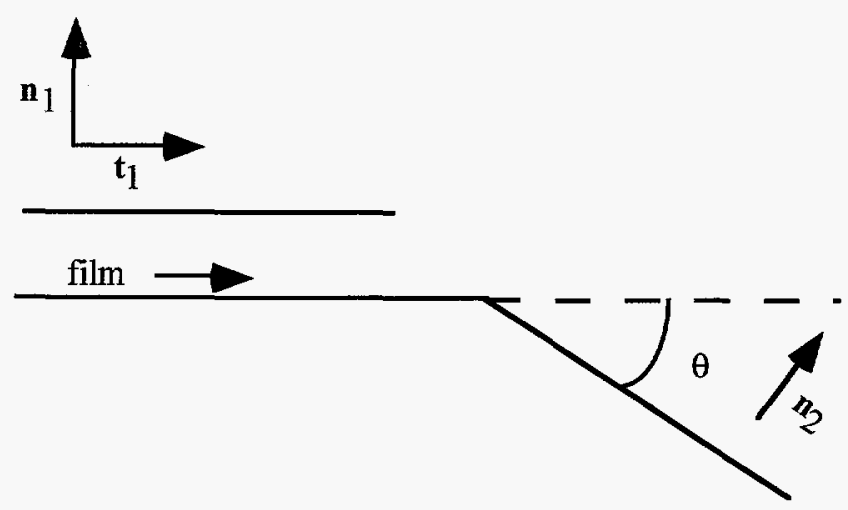

Figure 1: Geometry near a sharp corner

the wall need not lie in the plane of $\mathbf{n}_{1}$ and $\mathbf{n}_{2}$. The component of the relative film velocity in this plane and on surface 1 is $\left(\overline{\mathbf{u}}_{\ell}-\mathbf{v}_{w}\right) \cdot t_{1}$, where $t_{1}$ is the unit vector tangent to surface 1 in the plane of $\mathbf{n}_{1}$ and $\mathbf{n}_{2}$. The angle between $\mathbf{n}_{1}$ and $\mathbf{n}_{2}$ is $\theta$, the turning angle of the flow if it remains attached to the wall.

The physical picture is the following. As the liquid film approaches the corner on surface 1 , it will tend to keep its direction of flow and separate because of its inertia in the plane of $\mathbf{n}_{1}$ and $\mathbf{n}_{2}$ (Newton's first law). A low pressure region forms at the wall-side of the film, and the resulting pressure difference between the pressure on the gas-side, which is the gas pressure, and that on the wall-side, causes the flow to turn and remain attached to the corner. If, however, the liquid inertia is so large that the wall-side pressure drops to zero, then the liquid and wall no longer are pushing against each other, and the liquid film separates. These considerations and an examination of the mass and momentum balances for the liquid flow near the corner, lead to the following separation criterion:

$$
c_{s} \frac{\left[\rho_{\ell}\left(\overline{\mathbf{u}}_{\ell}-\mathbf{v}_{w}\right) \cdot \mathbf{t}_{1}\right]^{2} \sin \theta}{1+\cos \theta}>p_{\text {gas }}
$$

where $c_{s}$ is a constant we are currently taking to be 3 that depends on the shape of the pressure profile along the wall. Although this is a plausible picture of what occurs when films flow over sharp corners, it remains to be validated experimentally. Two dimensional numerical calculations of such flows would also be helpful; the authors know of no such recent calculations.

We wish to make two comments concerning the separation criterion (15). First, it may be surprising to some that surface tension does not enter. Surface tension does raise the pressure in the liquid film on its gas side, and this inhibits separation but can be shown to be a negligible effect. Second, it seems that the shear stress and film thickness should play major roles in causing separation, and this is not immediately apparent from Eq. (15). That the shear stress and film thickness are very important can be seen from Eq. (4), which shows that the film velocity relative to the wall is proportional to the shear stress and film thickness, and thus the separation criterion (15) depends quadratically on these quantities.

If the separation criterion is satisfied, then liquid film is converted to spray droplets at the edge where separation occurs. The new droplets are initialized with velocities equal to the mean film velocity $\overline{\mathbf{u}}_{\ell}$ and radii equal to half the film thickness $h$. Actually, computed results are insensitive to how the droplet properties are initialized upon separation, as the gas velocities are very large when separation occurs and according to the TAB droplet breakup model [14] the new droplets quickly break up into smaller, aerodynamically stable sizes that are accelerated to nearly the gas velocity.

\section{THE PARTICLENUMERICAL METHODFOR WALL FILMS}

When a spray particle impinges upon a wall, it is converted into a wall particle. Five quantities are kept for each wall particle: the particle position $\mathbf{x}_{p}$, the index $I 4_{p}$ of the computational cell in which the particle is located, an index $I F_{p}$ that gives the face (left, right, front, derriere, bottom, or top) of cell $I 4_{p}$ on which the particle is located, the particle mean temperature $T_{p}$, and the particle volume $V_{p}$. These are updated each computational cycle in a three step calculation.

1. First, for each cell face the mean film velocity $\overline{\mathrm{u}}_{\ell}$ is calculated.

2. Second, using the mean film velocity, the particle position and indices $I 4_{p}$ and $I F_{p}$ are updated.

3. Third, $T_{p}$ and $V_{p}$ are updated in a coupled, implicit calculation of heat and mass transfer.

In this section we briefly describe each of these steps, in the order in which they are performed by the KIVA-3 code.

CALCULATION OF THE FILM VELOCITY - The mean film velocity is a cell-face quantity, and all computational particles located on the same face move with the same velocity. Let us denote cell-face quantities with a subscript $\alpha$. The mean film velocity calculation begins with the calculation of the mass and momentum impingement sources, and the energy impingement source is also calculated at this time for later use in the wall particle temperature update:

$$
\begin{aligned}
& \left(\dot{M}_{\text {imp }}\right)_{\alpha}=\left(\sum_{\substack{p \text { on } \alpha \\
\text { this } \Delta t}} \rho_{\ell} V_{p}\right) /\left(\left|\mathbf{A}_{\alpha}\right| * \Delta t\right) \\
& \left(\dot{\mathbf{P}}_{\text {imp }}\right)_{\alpha}=\left(\sum_{\substack{p \text { on } \alpha \\
\text { this } \Delta t}} \rho_{\ell} V_{p} \mathbf{v}_{p}\right) /\left(\left|\mathbf{A}_{\alpha}\right| * \Delta t\right)
\end{aligned}
$$

and

$$
\left(\dot{Q}_{\mathrm{imp}}\right)_{\alpha}=\left[\sum_{\substack{p \text { on } \alpha \\ \text { this } \Delta t}} \rho_{\ell} V_{p} I_{\ell}\left(T_{p}\right)\right] /\left(\left|\mathbf{A}_{\alpha}\right| * \Delta t\right)
$$

where the sum is over all spray particles that have impinged on face $\alpha$ this time step and $\left|\mathbf{A}_{\alpha}\right|$ is the cell-face area. Next, the wall shear stress is calculated using Eq. (11) and dimensionless mass vaporization rates from the previous cycle. Finally, the film velocity on face $\alpha$ is obtained by solving Eq. (3):

$$
\begin{aligned}
\left(\overline{\mathbf{u}}_{\ell}\right)_{\alpha} & =\left\{\left(\tau_{w}\right)_{\alpha}(\mathbf{t})_{\alpha}+2 \frac{\mu_{\ell}\left(\bar{T}_{\alpha}\right)}{h_{\alpha}} \mathbf{v}_{w}+\left(\dot{\mathbf{P}}_{\mathrm{imp}}\right)_{\alpha}\right. \\
& \left.-\left[\left(\dot{\mathbf{P}}_{\mathrm{imp}}\right)_{\alpha} \cdot \mathbf{n}_{\alpha}\right] \mathbf{n}_{\alpha}+\left(\dot{M}_{\mathrm{imp}}\right)_{\alpha}\left[\left(\mathbf{v}_{w} \cdot \mathbf{n}_{\alpha}\right) \mathbf{n}_{\alpha}\right]\right\} \\
& /\left[2 \frac{\mu_{\ell}\left(\bar{T}_{\alpha}\right)}{h_{\alpha}}+\left(\dot{M}_{\mathrm{imp}}\right)_{\alpha}\right] .
\end{aligned}
$$

The film thickness $h_{\alpha}$ is obtained by summing the volumes of all particles on face $\alpha$ and dividing by the cell face area:

$$
h_{\alpha}=\frac{\sum_{p \text { on } \alpha} V_{p}}{\left|\mathbf{A}_{\alpha}\right|} \text {. }
$$


UPDATING THE FILM PARTICLE POSITIONS - The updating of the particle positions makes use of the so-called logical coordinates within a KIVA-3 computational cell [11]. Each KIVA-3 hexahedral cell is the image under a trilinear mapping, of a unit cube. The logical coordinates of a point $\mathbf{x}$ within a computational cell are the ordered triplet of coordinates within the unit cube whose image under this trilinear mapping is $\mathrm{x}$. We denote the logical coordinates by $(\xi, \eta, \zeta)$ and their associated physical point by $\mathbf{x}(\xi, \eta, \zeta)$.

The first step in updating the wall particle's position is to compute a provisional new particle position by

$$
\tilde{\mathbf{x}}_{p}=\mathbf{x}_{p}^{n}+\Delta t\left(\overline{\mathbf{u}}_{\ell}\right)_{\alpha},
$$

where $\alpha$ is the face upon which the particle is located. The provisional position $\tilde{\mathbf{x}}_{p}$ may be in another computational cell, and even if it is in the same cell it may not lie on the wall because the cell faces in KIVA-3 may not be planar. To find the final particle position, and possibly change the cell $I 4_{p}$ and face $I F_{p}$ on which the particle is located, we first solve for the logical coordinates $(\tilde{\xi}, \tilde{\eta}, \tilde{\zeta})$ of the provisional position. If $(\tilde{\xi}, \tilde{\eta}, \tilde{\zeta})$ indicate that the particle is in the same computational cell $I 4_{p}$, then its new position is determined by projecting the logical coordinates $(\xi, \eta, \zeta)$ onto the same cell face $I F_{p}$ the particle had at the old time level. For example, if at the old time level $\zeta=0.0$ then we set $\tilde{\zeta}=0.0$ and compute

$$
\mathbf{x}_{p}^{n+1}=\mathbf{x}(\tilde{\xi}, \tilde{\eta}, 0)
$$

If $(\tilde{\xi}, \tilde{\eta}, \tilde{\zeta})$ indicate that the particle has crossed a cell boundary, then one of these coordinates will either be greater than one or less than zero. This coordinate, and its value, tell us which edge of face $I F_{p}$ has been crossed. There are four possible cases for a particle that has crossed a cell edge:

1. It moves to the same logical face of a neighboring cell, e.g., bottom face to neighboring bottom face.

2. It turns an inside corner and is assigned to a different wall face of the same cell.

3. It turns an outside corner and is assigned to a different face of a neighboring cell around the corner.

4. It crosses an open boundary, in which case it leaves the system and is destroyed.

The quantities $I 4_{p}$ and/or $I F_{p}$ are updated as appropriate, and for cases 1-3, the out-of-bounds logical coordinate is either incremented or decremented by one to bring its value between zero and one. The new particle position is calculated using the logical coordinate mapping of the cell in which the particle is now located. At this time we also use the separation criterion (15) to determine whether or not to re-entrain the particle as a spray particle. It is possible that two of the logical coordinates $(\tilde{\xi}, \tilde{\eta}, \tilde{\zeta})$ are out-of-bounds, in which case a second pass through the above logic is performed to move the particle across two face edges.

UPDATING THE FILM PARTICLE TEMPERATURE AND VOLUME - The film particle temperature $T_{p}$ and volume $V_{p}$ are updated by solving coupled, implicit finite difference approximations to the film energy equation (5) and the interface conservation condition (6), utilizing the expressions for the heat and mass transfer rates (12) and (8) from the gas to the wall film. The difference approximation to the film energy equation is

$$
\begin{gathered}
\rho_{\ell} h_{\alpha} C_{v_{\ell}}^{n} \frac{T_{p}^{n+1}-T_{p}^{n}}{\Delta t}=\frac{2 \lambda_{\ell}\left(T_{p}^{n}\right)}{h_{\alpha}}\left[T_{s, p}-2 T_{p}^{n+1}+T_{w}\right] \\
+\left(\dot{Q}_{\mathrm{imp}}\right)_{\alpha}-I_{\ell}\left(T_{p}^{n}\right)\left(\dot{M}_{\mathrm{imp}}\right)_{\alpha},
\end{gathered}
$$

where $T_{s, p}$ is the surface temperature at the film/gas interface, which is obtained as a part of the implicit solution. The difference approximation to the interface conservation condition is

$$
\dot{Q}_{p}=\left(\dot{M}_{\text {vap }}\right)_{p} \mathcal{L}\left(T_{s, p}\right)+\frac{2 \lambda_{\ell}\left(T_{p}^{n}\right)}{h_{\alpha}}\left(T_{s, p}-T_{p}^{n+1}\right),
$$

where the mass vaporization rate is given by

$$
\begin{aligned}
\left(\dot{M}_{\mathrm{vap}}\right)_{p} & =H_{Y} \ln \left(\frac{1-Y_{v}}{1-Y_{v_{s, p}}}\right), \\
Y_{v_{s, p}} & =Y_{v_{\mathrm{eq}}}\left(T_{s, p}\right)
\end{aligned}
$$

and $H_{Y}$, given by Eq. (8a), depends on explicitly known information. The heat transfer rate is obtained from

$$
\dot{Q}_{p}=H_{T}\left(T_{p}^{n+1}-T_{s, p}\right),
$$

where the heat transfer coefficient $H_{T}$ is implicitly given in Eq. (12). $H_{T}$ depends on the dimensionless vaporization rate $M^{*}$, which is calculated using $\left(\dot{M}_{\text {vap }}\right)_{p}$ from Eq. (24).

These equations are solved for each particle by Newton iteration. Given a guess $T_{p}$ for the new particle temperature, the surface temperature is solved for using Eq. (22). Then the mass transfer rate can be calculated from Eq. (24), and finally the heat transfer rate is obtained from Eq. (25). We then test the residual in the solution of the interface conservation condition (23) and adjust $T_{p}$ until this residual is acceptably small for convergence.

Following convergence the particle volume is updated to account for its mass loss due to vaporization:

$$
V_{p}^{n+1}=V_{p}^{n}\left(1-\frac{\left(\dot{M}_{\mathrm{vap}}\right)_{p} \Delta t}{\rho_{\ell} h_{\alpha}}\right) .
$$

\section{EXAMPLE CALCULATIONS}

In this section we present the results of KIVA-3 calculations of open- and closed-valve injection in a generic pent-roof, twovalve engine. The intent here is to test the incorporation of the wall film model in its current state in a full KIVA-3 calculation of intake and compression in a realistic engine geometry. The results must be interpreted with caution because of the lack of a wall splash model and because the wall film model has thus far received little experimental validation; however, the findings show some interesting differences between open- and closedvalve injection. The calculations also demonstrate the potential usefulness of the model for predicting charge preparation in portinjected engines. On the negative side, the computations are quite lengthy, requiring about 10 hours on a Cray-YMP. 
ENGINE AND COMPUTATIOIALL PARAMETERS The parameters for the generic port-fuel-injected (PFI) engine are given in Table I, and the valve lift histories are given in Fig. 2. For the closed-valve case, injection timing was chosen so that most of the liquid fuel just adhered to the top of the intake valve at the time of intake valve opening $\left(-20^{\circ}\right)$. For the open-valve case, injection commenced at $60^{\circ}$ so that the time of maximum rate of impingement of liquid on the back of the valve coincided approximately with maximum valve lift at $90^{\circ}$. In both cases the injection velocity was constant, but the mass injection rate had a sinusoidal profile. The total liquid mass injected was chosen so that if all the injected fuel entered the cylinder, vaporized, and uniformly mixed, then the equivalence ratio in the cylinder would be approximately 2.0. The properties of gasoline were taken from Ref. [15-18].

Table I. Generic PFI Engine Parameters

$\begin{array}{ll}\text { Compression Ratio } & 9.6 \\ \text { Bore } & 8.26 \mathrm{~cm} \\ \text { Stroke } & 9.21 \mathrm{~cm} \\ \text { Connecting Rod } & 15.24 \mathrm{~cm} \\ \text { RPM } & 200 \\ \text { Wall and Valve } & \\ \quad \text { Temperatures } & 293 \mathrm{~K} \\ \text { Fuel } & \text { Gasoline } \\ \text { Valve Timings } & \\ \quad \text { IVO } & -20^{\circ} \\ \text { EVC } & 10^{\circ} \\ \text { IVC } & 210^{\circ} \\ \text { Injection Parameters } & \\ \text { Injection Duration } & 48^{\circ} \\ \text { Injected Mass } & 70 \mathrm{mg} \\ \text { Injection Velocity } & 1400 \mathrm{~cm} / \mathrm{s} \\ \text { Cone Angle } & 16^{\circ} \\ \text { Sauter Mean } & \\ \quad \text { Radius } & 25 \mu \mathrm{m} \\ \text { Starting CA } & -75^{\circ} \text { (closed-valve) } \\ \quad & 60^{\circ} \text { (open-valve) }\end{array}$

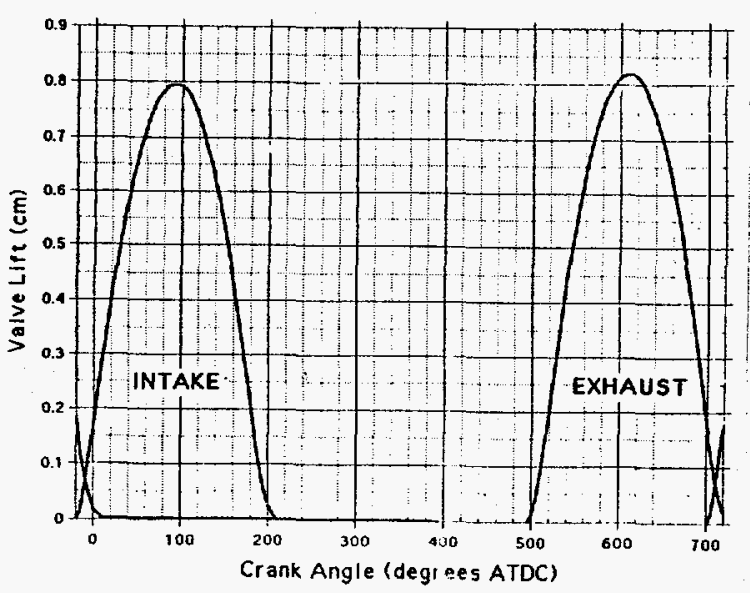

Figure 2: Valve lift history-generic PFI engine

Table II gives some of the computational parameters used in the calculations, and Fig. 3 shows a perspective view of the computational mesh at $\mathrm{BDC}$. The open-valve case was begun at $-15^{\circ}$ so that the intake event could be included in the calculation, and both cases were run to $345^{\circ}$ to obtain the computed charge distribution in the cylinder at approximately the time of ignition. As noted above, the Cray-YMP times of the calculations were approximately 10 hours; the same calculations run on an HP9000 were a factor of five to six slower.

Table II. Computational Parameters for PFI Engine Calculations Problem Duration $-75^{\circ}$ to $345^{\circ}$ (closed-valve) $-15^{\circ}$ to $345^{\circ}$ (open-valve)

Number of Vertices
at BDC
at TDC 17,900

Number of Time Steps 4,600 (closed-valve)

3,885 (open-valve)

Number of Computational Particles

Cray-YMP Computer Time HP-9000 Computer Time

1000

10 hours

$50-60$ hours

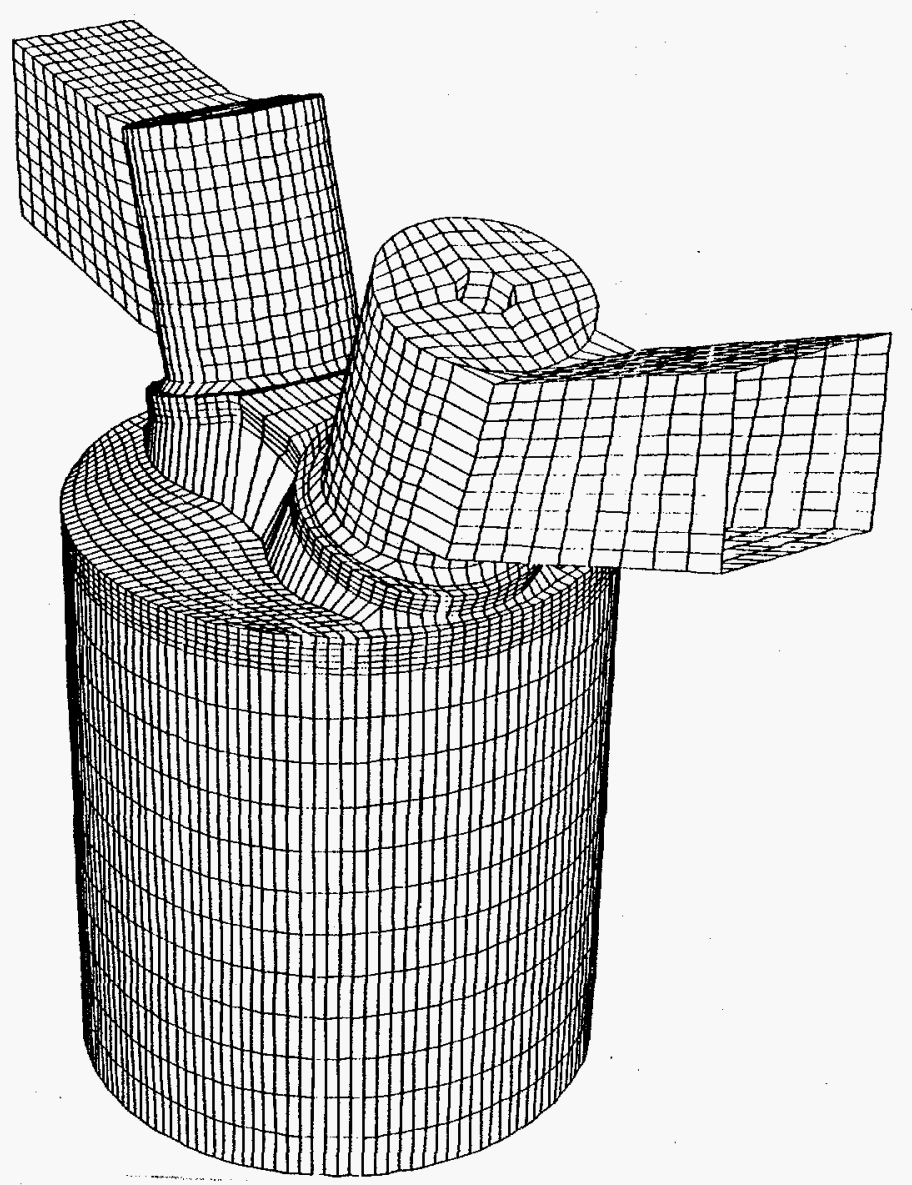

Figure 3: Perspective view of computational mesh for generic PFI engine

CLOSED-VALVE INJECTION RESULTS - We now give the computational results, first for the closed-valve injection case. Figure 4 gives plots of the spray and wall particle positions, gas velocities, and fuel vapor mass fractions in a plane through the axis of the cylinder and the axes of the valves. In the particle plots the velocities and positions of all particles in the calculation 
.
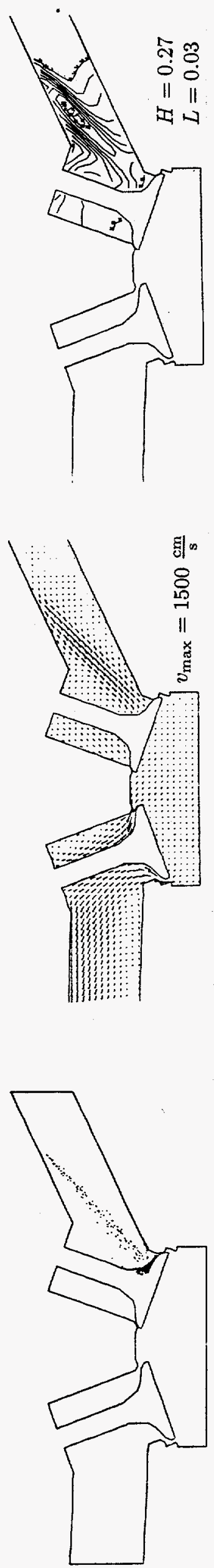
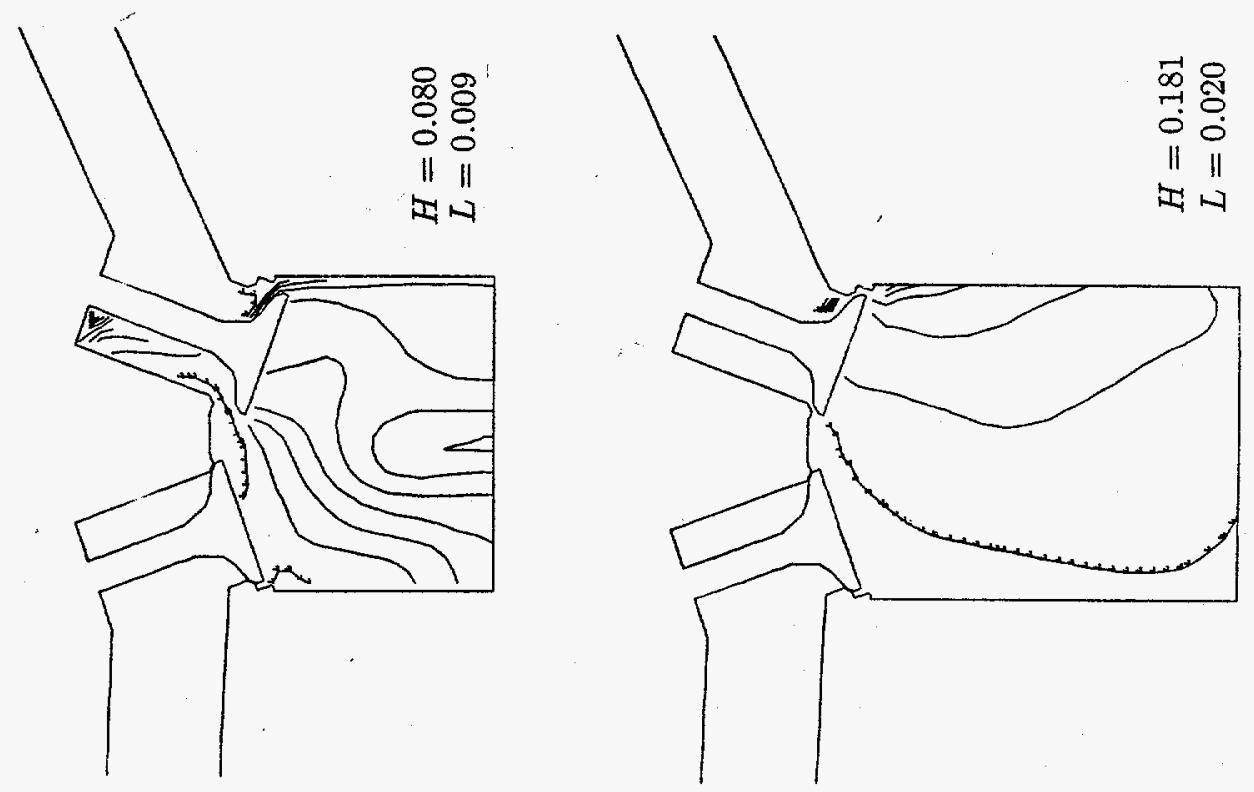

ல

II

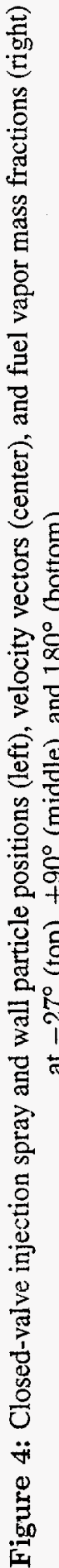


are projected onto the plotting plane $\mathrm{At}-27^{\circ}$, when injection has just finished, all spray particles appear to be impinging on the intake valve, and maximum gas velocities induced in the intake port by the spray are comparable to velocities around the exhaust port, which is still slightly open at this time. Maximum fuel vapor mass fractions of about 0.29 are seen in the core of the spray.

At $90^{\circ}$, at the time of maximum intake valve lift, all the liquid appears to lie on the intake valve. Strong intake gas velocities of about $1000 \mathrm{~cm} / \mathrm{s}$ have convected most of the fuel vapor into the cylinder, with the exception of a pocket of vapor in the stagnant region near the intersection of the valve stem and intake port wall. Also clearly visible is the mass source due to vaporization of the film on top of the valve.

The intake valve is nearly closed in Fig. 4 at $180^{\circ}$, so that the flows in the cylinder and intake port are nearly isolated from each other. The liquid film on the valve continues to vaporize, but this new vapor is now trapped in the intake port. The vapor concentrations are highly stratified in the cylinder, with mass fractions between 0.0 and 0.12 in the plotting plane.

Figure 5 gives plots at $345^{\circ}$ of the wall particle positions as seen from above the valve and of the fuel vapor mass fractions in a plane in the cylinder that is perpendicular to the cylinder axis. The particle positions clearly show a ring of liquid outlining the edge of the intake valve, with some liquid remaining on top of the valve. Charge stratification has been considerably reduced by mixing in the cylinder. The vapor mass fractions vary between 0.025 and 0.044 , with the highest values occurring near the intake port.

Much additional useful information is gained, and inferences from the detailed plots of Fig. 4 are confirmed, from plots in Fig. 6 of the histories of the global mass of fuel liquid and vapor. Shown are the histories of the total liquid mass on port walls, on the valve edge and face, on the valve top and stem, entrained in the port, and entrained in the cylinder; and the total vapor mass in the cylinder and port. The valve edge and face are those portions of the valve surface that are in the cylinder when the valve is closed. Figure 6 confirms that no liquid spray enters the cylinder and very little liquid $(<2.0 \mathrm{mg})$ impinges on the port walls. The liquid mass entrained in the port quickly rises at the start of injection at $-75^{\circ}$ to between 8 and $10 \mathrm{mg}$, remains nearly constant during injection, and then drops sharply to zero at the end of injection at $-27^{\circ}$. During injection the liquid mass on the valve top and vapor mass in the port rise steeply and nearly linearly. Immediately after injection the liquid mass on the valve drops slowly and the vapor mass rises slowly due to vaporization of the wall film. The intake valve opens at $-20^{\circ}$, but the intake flow does not start to sweep vapor from the port into the cylinder until about $+5^{\circ}$. At $+50^{\circ}$ nearly all the vapor has been convected into the cylinder, and the strong intake flows begin moving the wall film from the valve top to the valve edge. At no time in the calculation did we see liquid on the valve face or separation of liquid from the valve. Movement of liquid film from the valve top to its edge, and vaporization of this film, continue until about $180^{\circ}$. After valve closure at $210^{\circ}$ the liquid mass in wall films changes only slightly due to vaporization, and the vapor mass in the cylinder remains nearly constant at $21.71 \mathrm{mg}$, corresponding to an average equivalence ratio of 0.617 .

OPEN-VALVE INJECTION RESULTS - We now examine results of the calculation of open-valve injection and compare
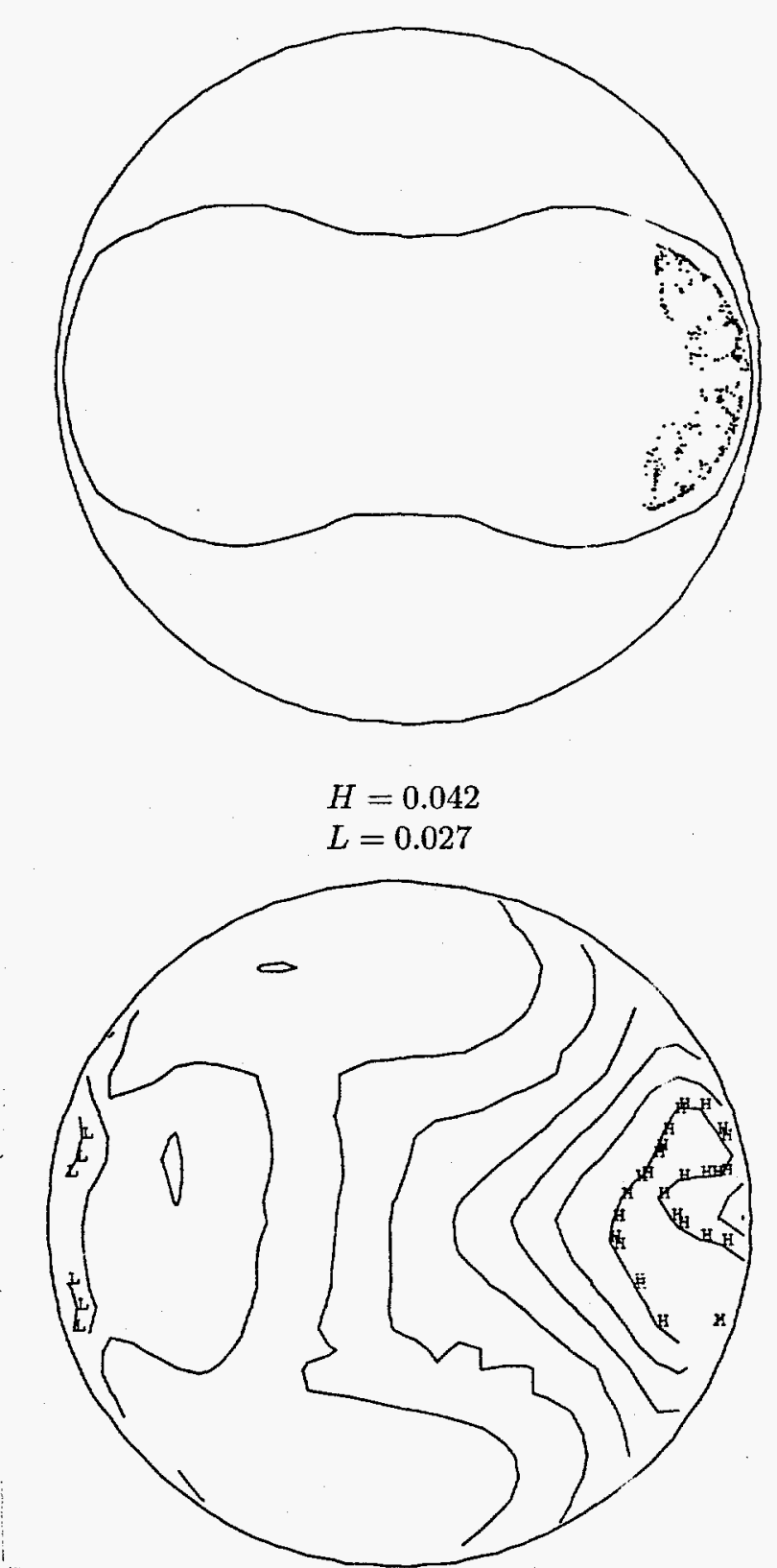

Figure 5: Top view of wall particle positions (top) and in-cylinder fuel vapor mass fractions (bottom) for closed-valve injection at $+345^{\circ}$

these with the closed-valve case. Figure 7 shows detailed plots similar to those of Fig. 4, but for the open-valve case at $90^{\circ}$ and $180^{\circ}$. The particle position plots of Fig. 7 appear to indicate that nearly all the spray is impinging on the valve and that none is entering the cylinder. This is confirmed in the global mass histories to be discussed below. Views of the spray from other angles show that the spray cone is widened by the diverging flow around the valve, but not enough to convect spray particles around the valve and into the cylinder. The velocity vectors of Fig. 7 show the deflection of the intake flow by the spray during injection. Highest vapor mass fractions of 0.19 occur in the core of the spray. This is lower than maximum vapor mass fractions seen in the closed-valve case in the core of the spray, Iig. 4, and indicates that higher vaporization rates may be occurring in this open-valve case. This will also be confirmed later.

In Fig. 7 at $180^{\circ}$ it is seen that although some of the wall film has moved down to the valve edge, most of the film remains on 


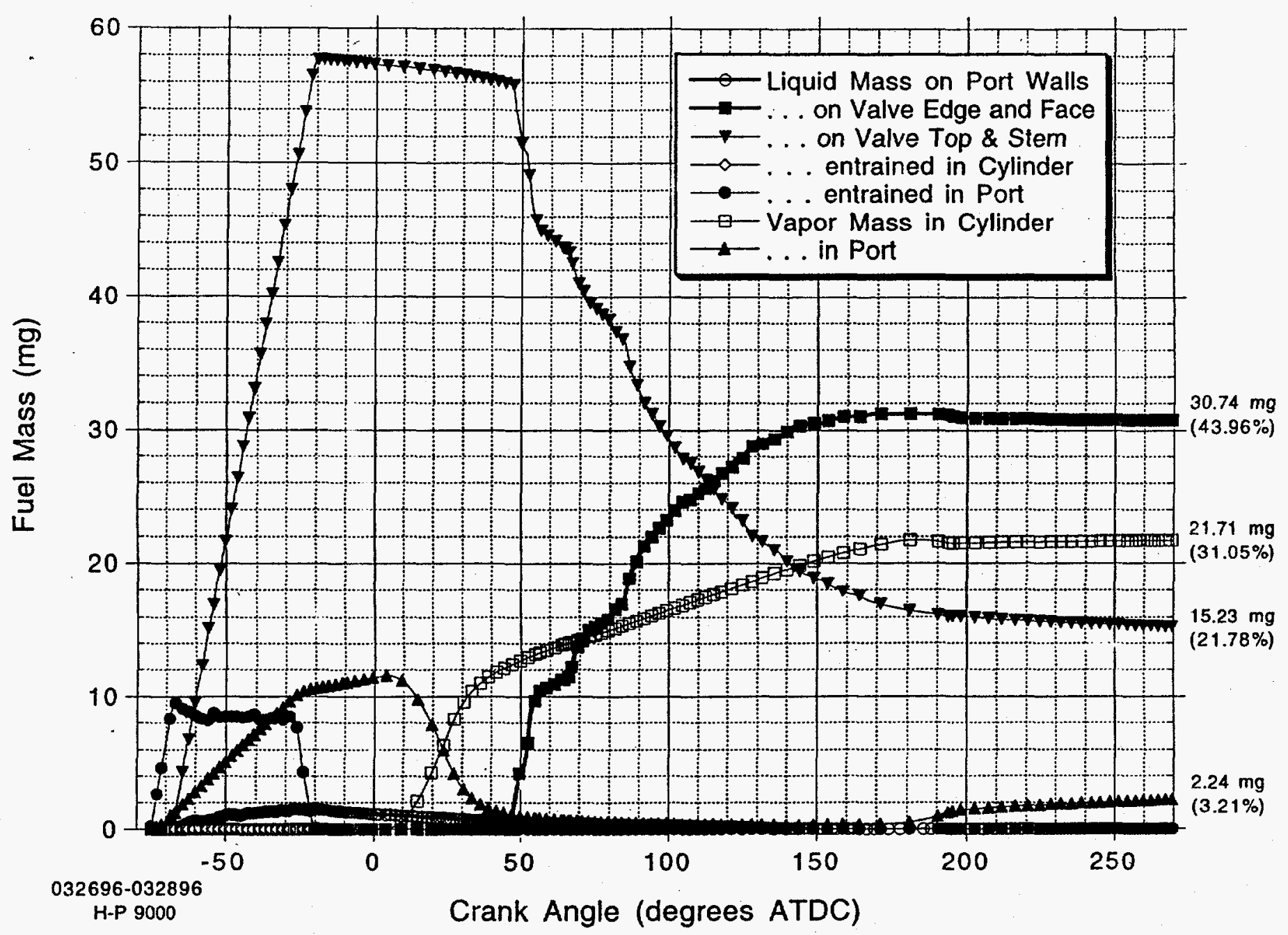

Figure 6: Histories of total fuel liquid and vapor mass for closed-valve injection

the valve top and stem because of the lower valve position at the time of injection relative to the closed-valve case. The velocity field of Fig. 7 at $180^{\circ}$ looks remarkably similar to that of Fig. 4, so that the differences in the timing of injection have had little effect on the flow field at this time. Fuel vapor in the cylinder is again highly stratified, with maximum mass fractions in the plotting plane of about 0.041 .

Figure 8, which should be compared with Fig. 5, gives an overhead view of wall particle positions on the valve and of fuel vapor mass fractions in the cylinder in a plane perpendicular to the cylinder axis for the open-valve case. There are two noteworthy features of the mass fraction plot of Fig. 8. First, the variation in mass fraction is between 0.019 and 0.028 , indicating that there is much less vapor in the cylinder than in the closedvalve case. Second, the vapor distribution is much different than in Fig. 5, with maximum concentrations near the cylinder walls and between the intake and exhaust valves.

That there is less vapor in the cylinder is confirmed in Fig. 9, which gives the histories of the global fuel liquid and vapor at various locations for the open-valve case and should be compared with Fig. 6. The average equivalence ratio in the cylinder at $345^{\circ}$ is 0.430 , which is about two-thirds of the value for the closed-valve case. Also confirmed by Fig. 9 are that no liquid enters the cylinder and that very little of the wall film moves onto the valve edge.

To see more clearly why open-valve injection results in less vapor in the cylinder of our generic engine, it is instructive to examine the plots of Fig. 10 of total vapor mass versus crank angle relative to the start of injection. Immediately apparent from this figure is the fact that for both cases vaporization rates are faster while the liquid is a spray rather than in wall films. It is also seen that the vaporization rate is higher in the open-valve case during the $50^{\circ}$ of injection, because the intake flow coincides with injection and promotes vaporization in this case. In the open-valve case, however, there are only $150^{\circ}$ between start of injection and intake valve closure, compared with $285^{\circ}$ for the closed-valve case. Also the wall films in the closed-valve case see the high intake flow velocities, whereas in the open-valve case the intake flow velocities have slowed considerably after the injection event. Thus more vapor is obtained with closedvalve injection primarily because the wall films have more time to vaporize, but also because the rate of vaporization of the films is somewhat higher.

These results are likely to change, particularly for the openvalve case, when a model for wall splash is incorporated into KIVA-3. In the closed-valve case droplets produced by wall splash have time to travel to neighboring walls and adhere to them before the intake valve opens. For closed-valve injection, 

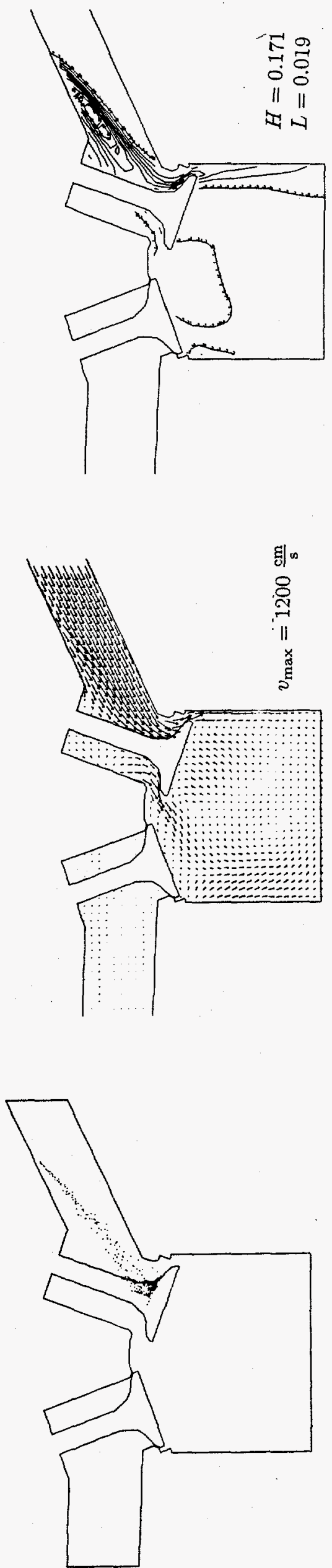

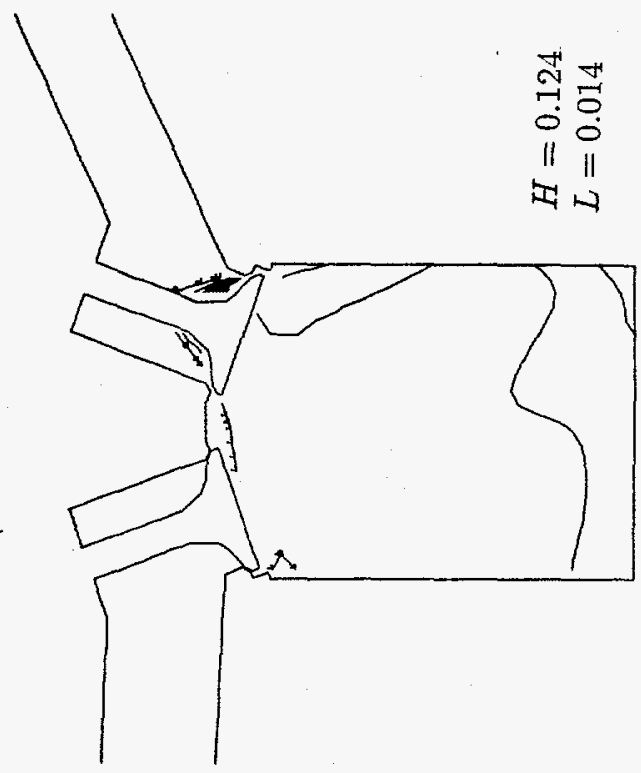

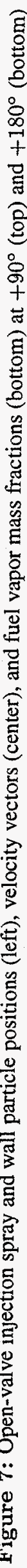
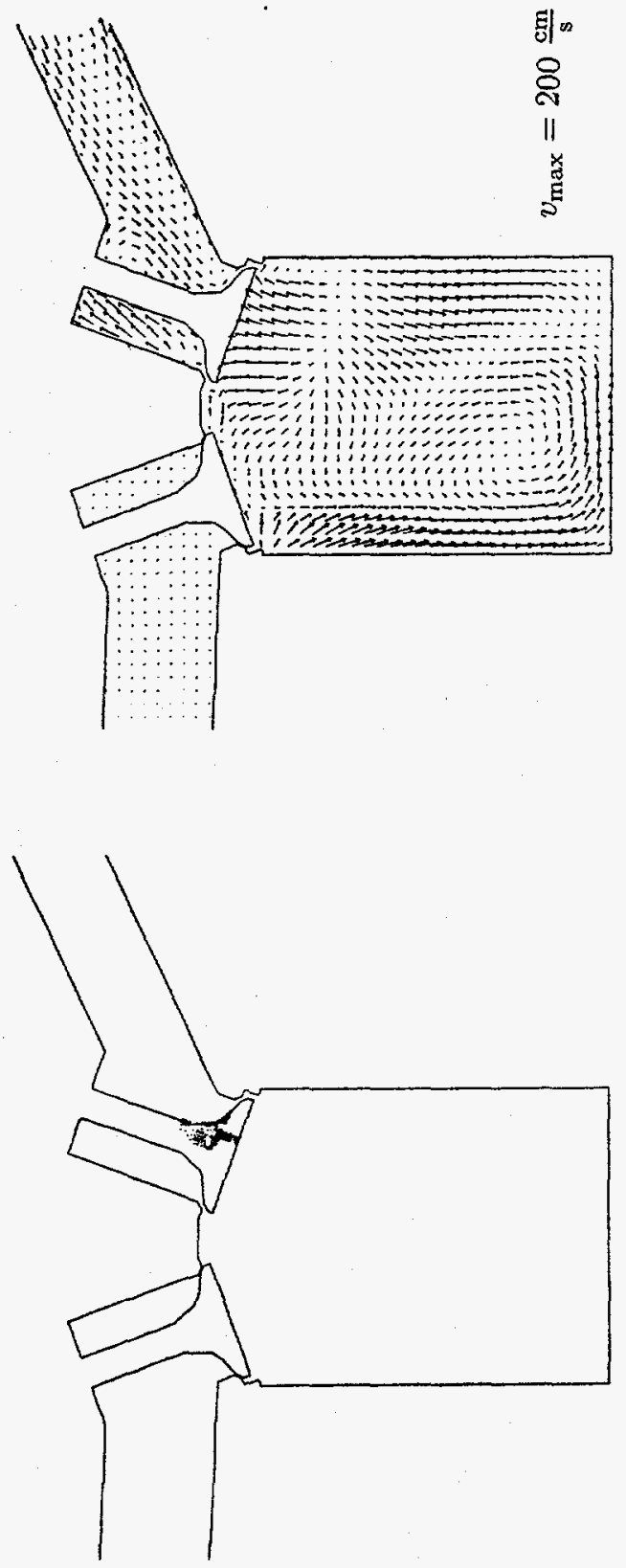

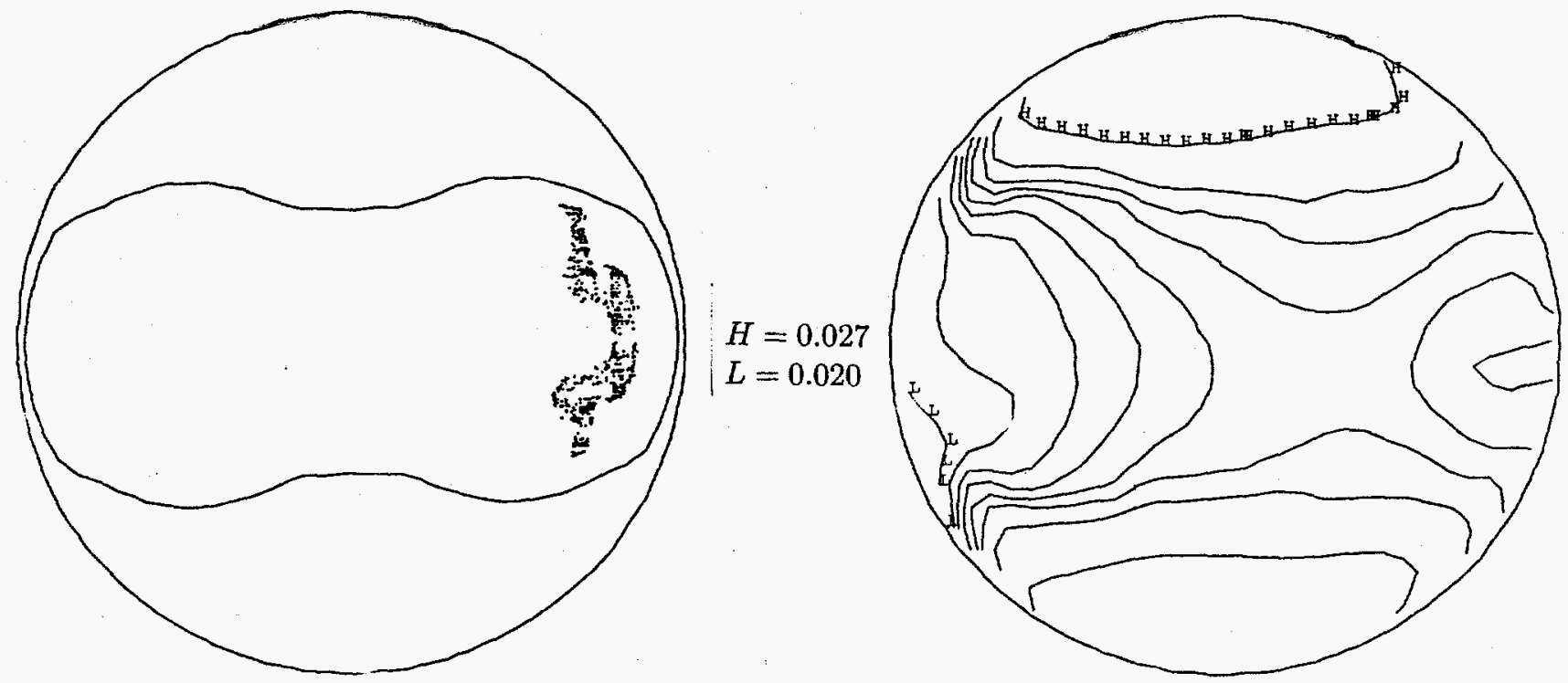

Figure 8: Top view of wall particle positions (left) and in-cylinder fuel vapor mass fractions (right) for open-valve injection at $+345^{\circ}$

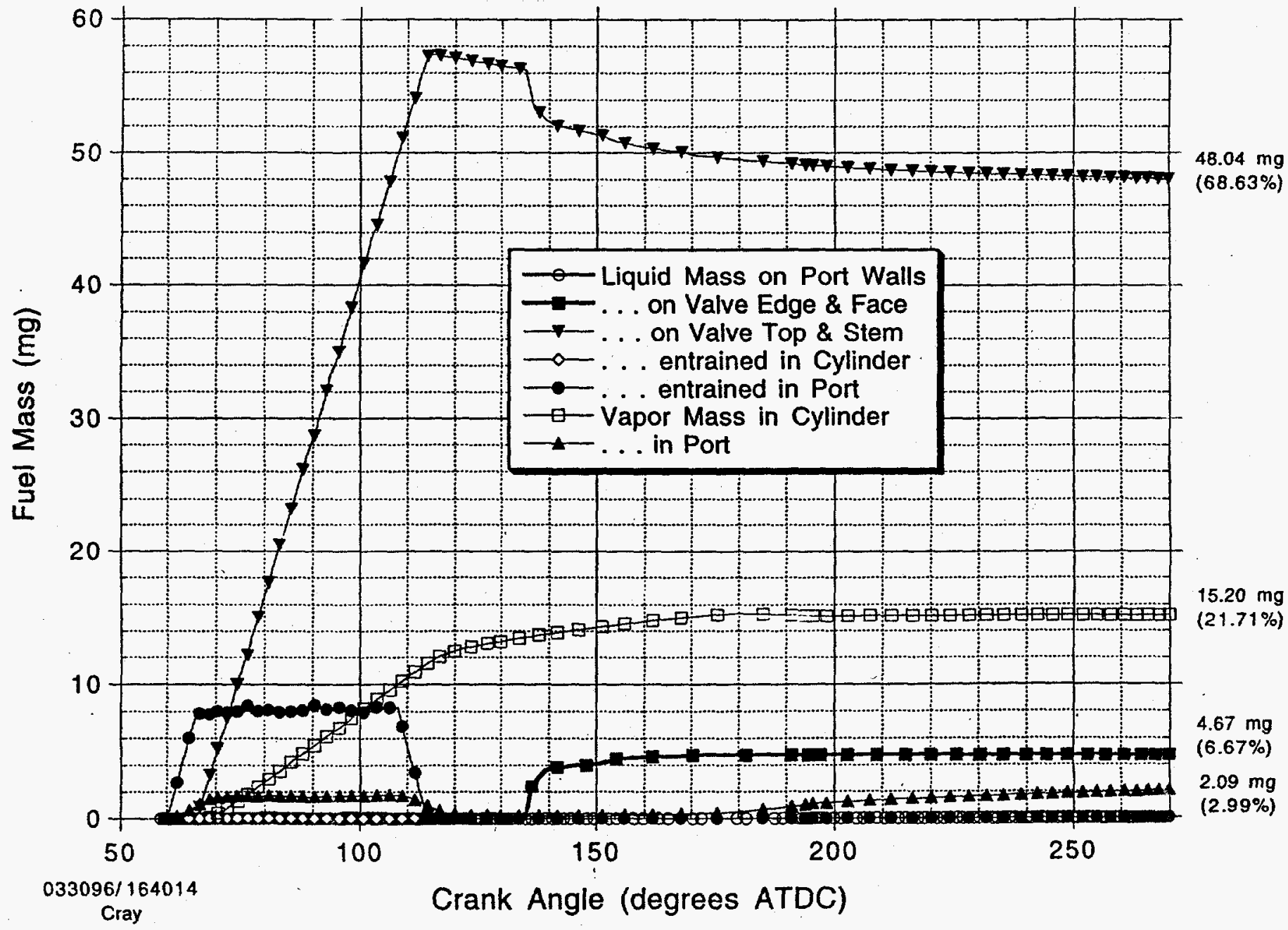

Figure 9: Histories of total fuel liquid and vapor mass for open-valve injection 


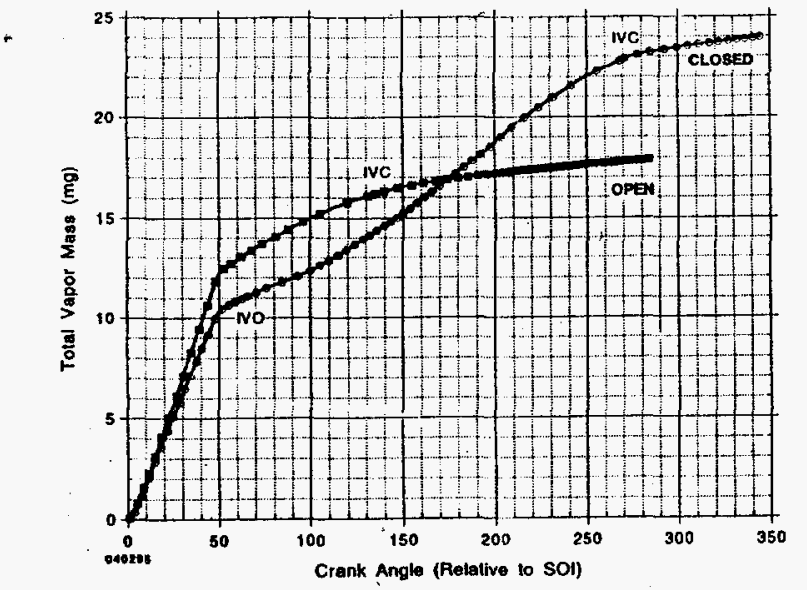

Figure 10: Total vapor mass vs. crank angle relative to the start of injection for closed (circles) and open (squares) valve injection

however, the product drops of wall splash are immediately subjected to the intake gas flows and are likely to be convected into the cylinder. This could significantly raise the in-cylinder fuel vapor concentrations in the open-valve case. Thus development of a wall splash model is our highest priority in future research.

\section{SUMMARY}

This paper has presented a new particle method for the calculation of wall film flows and described its implementation in the KIVA-3 computer code. The equations of the model are based on a thin film approximation, according to which inertial terms in the film momentum equation are neglected but which accounts for unsteady heating in the film energy equation. The particle nature of the numerical method enables very accurate calculation of convection of the wall film. The model includes new wall functions that predict vaporization rates from the films and that account for the inhibition of momentum and energy transport due to vaporization. A new inertial criterion is also included to predict separation and re-entrainment of film flows from walls.

Two KIVA-3 calculations of the intake and compression strokes of a generic two-valve, port-fucl-injected engine were then presented. The calculations compared open- and closedvalve injection cases for the first injection cycle in a cold engine. The current model predicts that closed-valve injection gives higher in-cylinder vapor concentrations because in both cases the sprays impinged almost entirely on the intake valve but in the closed-valve case there was more time for vaporization of the resulting wall films due to the advanced injection timing. The calculations demonstrate the potential of the complete KIVA-3 model for predicting charge preparation in port-fuel-injected engines.

Future work will center on incorporating a model for wall splash in regions of spray impingement, on reducing computational times, and on experimental validation of the wall film model.

\section{ACKNOWLEDGMENTS}

The authors would like to thank T. D. Butler and N. L. Johnson for many helpful suggestions. This work was supported by the U.S. Department of Energy's Office of Transportation Technologies.

\section{REFERENCES}

1. DOE Working Group Meeting, Princeton University, March 1995.

2. Yoshikawa, Y. et al., "Numerical Simulation System for Analyzing Fuel Film Flow in Gasoline Engines, SAE paper 930326, 1993.

3. Nagaoka, M., H. Kawazoe, and N. Namura, "Modeling Fuel Spray Impingement on a Hot Wall for Gasoline Engines," SAE paper 940525, 1994.

4. Ahmadi-Befrui, B., N. Uchil, A. D. Gosman, and R. I. Issa, "Modeling and Simulation of Thin Liquid Films Formed by Spray-Wall Interaction,” SAE paper 960627, 1996.

5. Stanton, D., and C. Rutland, "Modeling Fuel Film Formation and Wall Interaction in Diesel Engines," SAE paper 960628 , 1996.

6. Zhao, F., M. Lai, and D. Harrington, "The Spray Characteristics of Automotive Port Fuel Injection-A Critical Review," SAE paper 950506, 1995.

7. Naber, J., and P. Farrell, "Hydrodynamics of Droplet Impingement on a Heated Surface," SAE paper 930919, 1993.

8. Launder, B. E., and D. B. Spalding, "The Numerical Computation of Turbulent Flows," Computer Methods in Applied Mechanics and Engineering, 3, 269-289, 1974.

9. Harlow, F. H., "The Particle-in-Cell Computing Method for Fluid Dynamics," in Methods in Computational Physics, Vol. III, B. Alder, S. Fernbach, and M. Rotenberg, eds., Academic Press, New York, 1964.

10. Harlow, F. H., J. E. Welch, J. D. Shannon, and B. J. Daly, "The MAC Method," Los Alamos Scientific Laboratory report LA-3425, 1965.

11. Amsden, A. A., P. J. O'Rourke, and T. D. Butler, "KIVAII: A Computer Program for Chemically Reactive Flows with Sprays," Los Alamos National Laboratory report LA-1 1560-MS, 1989.

12. Eckhause, J. E., and R. D. Reitz, "Modeling Heat Transfer to Impinging Fuel Sprays in Direct-Injection Engines," Atomization and Sprays, 5, 2, 213, 1995.

13. Amsden, A. A., "KIVA-3: A KIVA Program with BlockStructured Mesh for Complex Geometries," Los Alamos National Laboratory report LA-12503-MS, 1993.

14. O'Rourke, P. J., and A. A. Amsden, "The TAB Method for Numerical Calculation of Spray Droplet Breakup," SAE paper 872089, 1987. 
15. Rose, J. W., and J. R. Cooper, Technical Data on Fuel, - John Wiley \& Sons, New York, 1977.

16. Vargafrik, N. B., Tables on the Thermophysical Properties of Liquids and Gases, John Wiley \& Sons, New York, 1975.

17. Maxwell, J. B., Data Book on Hydrocarbons, D. Van Nostrand Company, Inc., Princeton, NJ, 1958.

18. "Handbook of Aviation Fuel Properties," published by Coordinating Research Council, Report No. 530, SAE, Warrendale,
PA, 1983.

\section{DISCLAIMER}

This report was prepared as an account of work sponsored by an agency of the United States Government. Neither the United States Government nor any agency thereof, nor any of their employees, makes any warranty, express or implied, or assumes any legal liability or responsibility for the accuracy, completeness, or usefulness of any information, apparatus, product, or process disclosed, or represents that its use would not infringe privately owned rights. Reference herein to any specific commercial product, process, or service by trade name, trademark, manufacturer, or otherwise does not necessarily constitute or imply its endorsement, recommendation, or favoring by the United States Government or any agency thereof. The views and opinions of authors expressed herein do not necessarily state or reflect those of the United States Government or any agency thereof. 